Clemson University

TigerPrints

$2-2020$

Lionfish (Pterois volitans) as biomonitoring species for oil pollution effects in coral reef ecosystems

Peter van den Hurk

Ian Edhlund

Ryan David

Jacob J. Hahn

Michel J. McComb

See next page for additional authors

Follow this and additional works at: https://tigerprints.clemson.edu/bio_pubs

Part of the Biology Commons 


\section{Authors}

Peter van den Hurk, Ian Edhlund, Ryan David, Jacob J. Hahn, Michel J. McComb, Elizabeth L. Rogers, Emily Pisarski, Katy Chung, and Marie DeLorenzo 


\title{
Title: Lionfish (Pterois volitans) as biomonitoring species for oil pollution effects in coral reef ecosystems.
}

Authors: , Peter van den Hurk ${ }^{1,6}$, Ian Edhlund ${ }^{6}$, Ryan Davis ${ }^{1}$, Jacob J. Hahn², Michel J. McComb ${ }^{1}$, Elizabeth L. Rogers ${ }^{3}$, Emily Pisarski ${ }^{4}$, Katy Chung ${ }^{4}$, Marie DeLorenzo ${ }^{5}$

\author{
Affiliation: \\ ${ }^{1}$ Department of Biological Sciences, College of Science, Clemson University \\ 2 Department of Genetics and Biochemistry, College of Science, Clemson University \\ ${ }^{3}$ Department of Animal and Veterinary Sciences, College of Agriculture, Forestry and Life \\ Sciences, Clemson University \\ ${ }^{4}$ CSS, Inc., under contract to NOAA \\ ${ }^{5}$ NOAA, National Ocean Service, National Centers for Coastal Ocean Science, Charleston, SC \\ ${ }^{6}$ Graduate Program in Environmental Toxicology, Clemson University
}

\begin{abstract}
:
With oil spills, and other sources of aromatic hydrocarbons, being a continuous threat to coral reef systems, and most reef fish species being protected or difficult to collect, the use of the invasive lionfish (Pterois volitans) might be a good model species to monitor biomarkers in potentially exposed fish in the Caribbean and western Atlantic. The rapid expansion of lionfish in the Caribbean and western Atlantic, and the unregulated fishing for this species, would make the lionfish a suitable candidate as biomonitoring species for oil pollution effects. However, to date little has been published about the responses of lionfish to environmental pollutants. For this study lionfish were collected in the Florida Keys a few weeks after Hurricane Irma, which sank numerous boats resulting in leaks of oil and fuel, and during the winter and early spring after that. Several biomarkers indicative of exposure to PAHs (bile fluorescence, cytochrome P450-1A induction, glutathione S-transferase activity) were measured. To establish if these biomarkers are inducible in PAH exposed lionfish, dosing experiments with different concentrations of High Energy Water Accommodated Fraction of crude oil were performed. The results revealed no significant effects in the biomarkers in the field collected fish, while the exposure experiments demonstrated that lionfish did show strong effects in the measured biomarkers, even at the lowest concentration tested (0.3\% HEWAF, or $25 \mu \mathrm{g} / \mathrm{I} \mathrm{PAH} 50)$. Based on its widespread distribution, relative ease of collection, and significant biomarker responses in the controlled dosing experiment, it is concluded that lionfish has good potential to be used as a standardized biomonitoring species for oil pollution in its neotropical realm.
\end{abstract}

\section{Introduction:}

In late August through early September of 2017, Hurricane Irma swept through the Caribbean with winds reaching up to $82.7 \mathrm{~m} / \mathrm{s}$. As the eye of the hurricane passed directly over the Florida Keys, a large number of recreational and fishing boats that were moored in marinas and private 
docks overturned and sank. Oil and fuel from these vessels leaked into the ocean, polluting near shore environments, and potentially the reef communities further offshore. Reef researchers and local recreational scuba divers were concerned these hydrocarbon leaks could have an effect on the reefs in the Florida Keys.

Oil hydrocarbons can cause significant damage to reefs if the coral species are getting in contact with the oil (Turner and Renegar, 2017). Oil can kill the coral, and can cause difficulties in growth, reproduction, and development of the larvae. Not only coral species, but the entire ecosystem of a reef, including fish, crustaceans and other invertebrates that live within the reef ecosystem will suffer from oil spills. This can also cause health issues to any larger predatory fish that consumes smaller exposed fish and can lead to trophic transfer up the food chain. The Florida Keys reefs have been under enormous stress for several decades due to uncontrolled wastewater discharges, introduced pathogens, recreational and commercial fishing pressure, and increasing seawater temperature and acidification as a result of global climate change (Futch et al., 2010; Ateweberhan et al., 2013; Kemp et al., 2018; Toth et al., 2019). Additional stress by direct hurricane damage and indirect through the release of oil and fuel from sunken boats may further deteriorate the reefs or hamper the recovery from other stressors.

To monitor the effects of environmental pollutants on aquatic and marine organisms, biomarkers have been identified and implemented as early warning signals for the detrimental effects of exposure to those pollutants (Van der Oost et al., 2003). In large animals, like sea mammals, non-invasive techniques are available to measure biomarker responses without killing the animal. However, in smaller organisms like most reef dwellers, tissue specimens need to be collected after the animals are taken out of the water, which usually involves euthanizing the organism. This creates a problem for researchers in highly protected reef environments; most species are protected or have at least limited harvest time restrictions. To avoid these collection restrictions, especially in rapid response projects that don't allow for lengthy permit applications, the collection of undesired invasive species may be a solution to obtain biomarker results that indicate exposure to, and effects of, released pollutants. In the Caribbean, the invasive lionfish (Pterois volitans) may fulfill the requirements of an abundant coral reef species for which there are no sampling restrictions.

The lionfish is an invasive species to the Caribbean, originally native to the Indo-Pacific region. It was first noticed in 1985 off the Atlantic coast of Florida, and has gradually expanded into the Caribbean and along the western Atlantic coasts (Bors et al., 2019). Although the species is a voracious feeder on a large variety of smaller reef fish, recent reports question earlier suggestions that this invasion would severely diminish reef fish diversity in the Caribbean (Hackerott et al., 2017). The potential threat of the ecological effects of the expansion of lionfish has spurred numerous round-up derbies by local scuba diver communities, with mixed results (Usseglio et al., 2017).

The goal of this project was to evaluate if lionfish can be used as biomonitoring species for the effects of oil spills in coral reef ecosystems. To achieve this goal, biomarkers that are typically used to measure hydrocarbon exposure (bile fluorescence, ethoxyresorufin-O-deethylase 
(EROD) activity, glutathione S-transferase (GST) activity) were measured in lionfish that were collected at several time intervals after Hurricane Irma had created oil spills from sunken boats in the Florida Keys. In addition, lionfish were exposed in controlled experiments to concentration ranges of High-Energy Water Associated Fractions (HEWAFs) of crude oil to verify that these biomarkers in this species are actually responsive to aromatic hydrocarbons. No published papers were found on the effects of oil hydrocarbons on lionfish, which makes these studies unique and relevant for monitoring the effects of future oil spills on coral reef species.

\section{Materials and Methods:}

Fish and tissue collection

Lionfish were collected by spearfishing from 11 locations in the Middle Keys area, south and southeast of Marathon, Florida (FL) (Figure 1). The first collection trip was from October 14-16, 2017, and is labeled as "Fall", the second collection trip, labeled "Winter", was from December 14-16, 2017, and the third trip in "Spring" was from March 11-21, 2018. Exact sampling locations, numbers of fish and size range are provided in Supplemental Information Table 1. Locations were selected based on prior knowledge of lionfish availability, and to obtain a variety of depth and distance to marinas as potential sources of oil pollution. Collected fish were kept on ice until landing, and were measured for weight and body length before they were dissected to remove their livers and gallbladders. Livers were wrapped in labeled aluminum foil, and gallbladders were sealed in cryotubes. All samples were frozen in liquid nitrogen until arrival back at the lab in Clemson, South Carolina (SC), where they were stored at $-80^{\circ} \mathrm{C}$ until further processing.

Fish for the first exposure experiment were collected from May 1-6, 2018; fish for the second exposure experiment were collected March 25-29, 2019. Fish for the exposure experiments were collected at several of the earlier mentioned locations south of Marathon, FL, with handheld lobster nets, and were kept as mixed population in an outdoors flow through system in Conch Key, Fl. Fish that were collected at deeper sites had their swimbladder vented with a large needle to adjust them to sea surface atmospheric pressure. Fish were transported in an aerated live well to the NOAA-NOS lab in Charleston SC, where they were acclimated to local conditions for 3-7 days and fed a mixture of grass shrimp (Palaemonetes pugio) and mummichogs (Fundulus heteroclitus) until transfer to the exposure tanks. 

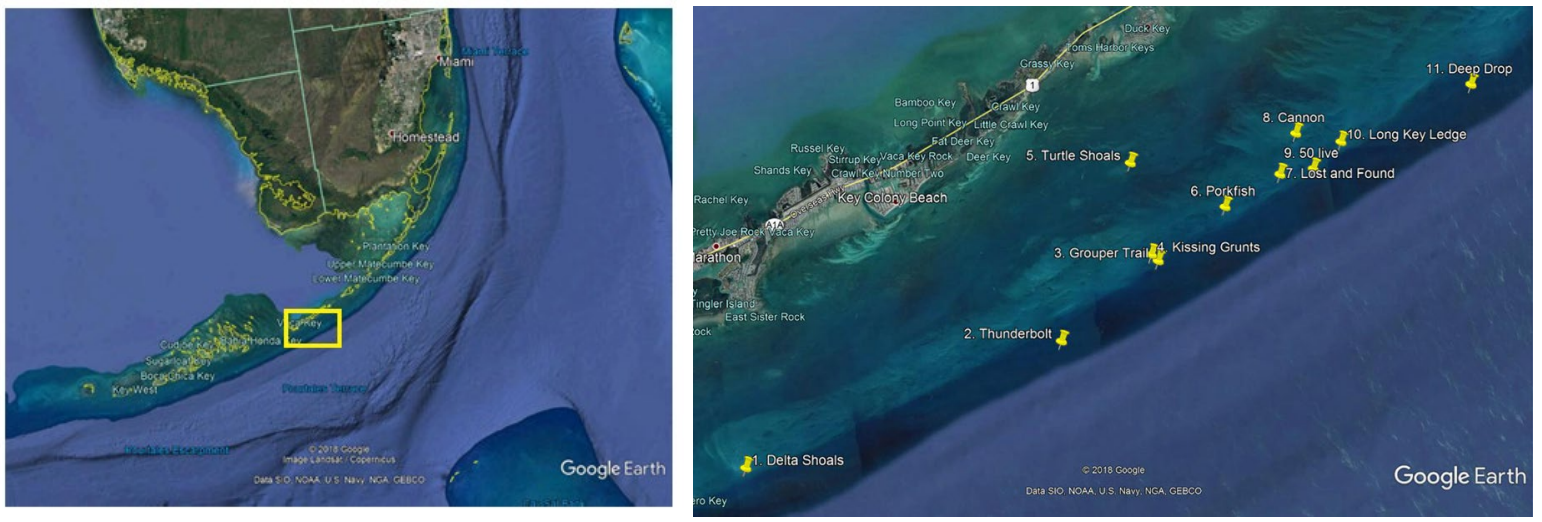

Figure 1. Sampling sites in the Florida Keys south of the island of Marathon; panel A shows general area in south Florida, panel B shows detailed location of each individual site, numbered 1-11 from west to east. Geographical coordinates and depth of each location are provided in Supplemental Information Table 1.

\section{Experimental setup}

For the 96h exposure experiments, four fish per treatment were individually housed in 10-liter containers for the smaller fish $(<200 \mathrm{~mm}$ ) and 35-liter tanks for the larger animals (>200 mm). Seawater for all bioassays was acquired from Charleston Harbor estuary (N 32 $45^{\prime} 11.52$ "; W 7953'58.31'), filtered (5 $\mu \mathrm{m})$, UV-sterilized, and activated carbon filtered. Tanks were covered with aluminum foil, aerated using a $1 \mathrm{ml}$ glass pipette attached to tubing, and fish were not fed during the exposure. Fish were exposed to different concentrations of High Energy Water Accommodated Fraction (HEWAF) of Louisiana Sweet Crude (LSC) oil. This $1 \mathrm{~g} / \mathrm{l} \mathrm{HEWAF} \mathrm{was}$ prepared by mixing 3.75 I of seawater (32 ppt) with fresh LSC oil ( $3.75 \mathrm{~g}$ by mass) in a commercial blender, on low power, for $30 \mathrm{~s}$. The mixture was transferred to a glass aspirator bottle with the bottom outlet closed with Tygon tubing and a glass stopper. The mixture was allowed to settle for $1 \mathrm{~h}$ in the dark, after which the bottom outlet was opened, and the HEWAF was dispensed into a collection container, without disturbing the upper slick layer. The $100 \%$ HEWAF was then diluted with seawater to achieve the exposure concentrations. The HEWAF was diluted for the first experiment to exposure concentrations of $25 \%, 8.33 \%$ and $2.78 \%$ HEWAF and a seawater control. For the second experiment the exposure concentrations were lowered to $2.78 \%, 0.9 \%$ and $0.3 \%$ HEWAF and a seawater control. Treatments were renewed after 48h. After the exposure, fish were euthanized in $1 \mathrm{~g} / \mathrm{l}$ tricaine methanesulfonate (MS-222), weighted and measured, dissected, and tissues were preserved as described above for the field collected animals.

\section{Chemical analysis}

Water samples for the $100 \%$ HEWAF and all treatments (composite of four replicates) were collected immediately after dosing $(\mathrm{t}=0 \mathrm{~h}$ and $\mathrm{t}=48 \mathrm{~h})$. Polynuclear aromatic hydrocarbon $(\mathrm{PAH})$ concentrations in the exposure tanks were analyzed according to standard NOAA-NOS 
procedures. Briefly, samples were acidified to a $\mathrm{pH}$ of 2 , isotopically labeled internal standards were added, and extracted via liquid/liquid extraction with dichloromethane and hexane.

Extracts underwent a cleanup step using silica solid phase extraction (SPE) and spiked with a recovery standard prior to analysis using gas chromatography mass spectrometry (GC/MS Agilent 6890/5973N). The GC/MS contained a DB17ms analytical column $(60 \mathrm{~m} \times 0.25 \mathrm{~mm} \times$ $0.25 \mu \mathrm{m}$ ) and was operated in selected ion monitoring mode. A total of 50 PAHs were analyzed, including both parent and alkylated PAHs, and are reported as $\mathrm{PPAH} 50$.

\section{Bile analysis}

To measure PAHs that were absorbed and excreted by the fish, bile samples were analyzed for fluorescence at excitation/emission wavelength pairs that are specific for 2-ring, and 5-ring PAHs. Gall bladders of 4 fish per treatment were thawed, and bile was released into dark microcentrifuge tubes. Bile volume was measured and recorded, and if less than $50 \mu \mathrm{l}$, deionized water was added to bring the volume up to $50 \mu$ l. Several consecutive serial dilutions $(1: 20,1: 33,1: 66$ for the field samples, 1:12.5, 1:125, 1:250, 1:2500 for the experimental samples) were prepared in dark microcentrifuge tubes using a 50:50 methanol:water solution. Fluorescence of aromatic compounds (FACs) was then measured in three replicate aliquots from each dilution at 290/335 nm, and 380/430 nm excitation/emission wavelengths on a BioTek Synergy $\mathrm{H} 1$ plate reader (BioTek, Winooski, VT). Raw fluorescence data were plotted against dilution, and the values of the highest dilution not showing inner filter effects were used for further calculations. The FAC values were corrected using a methanol:water blank and normalized to bile volume (van den Hurk, 2006).

\section{Liver enzyme activities}

Activities of two inducible enzymes that are involved in the metabolism of toxicants were measured in liver homogenates. Livers were weighed and individually homogenized with a glass Potter-Elvehjem homogenizer in $2 \mathrm{ml}$ of chilled homogenization buffer (van den Hurk, 2006). Liver homogenates were then centrifuged at $10,000 \times \mathrm{g}$ and $4^{\circ} \mathrm{C}$ for $20 \mathrm{~min}$, after which the supernatant (S9 fraction) was divided into three aliquots for later determination of ethoxyresorufin-O-deethylase (EROD) activity, glutathione S-transferase (GST) activity, and total protein concentration. The EROD and GST aliquots were stored in a $-80^{\circ} \mathrm{C}$ freezer and the protein aliquot was stored in a $-20^{\circ} \mathrm{C}$ freezer prior to analysis. Protein concentrations were measured with a bicinchoninic acid (BCA) Protein Assay Kit (Pierce, Rockford, IL), using bovine serum albumin (BSA) to prepare the standard curve.

For the EROD assay, liver S9 fractions were diluted to $1.0 \mathrm{mg} / \mathrm{ml}$ total protein concentration, and $100 \mu$ l of diluted S9 fractions (in duplicate) were added to a black 96 -well plate. The reaction was started by adding $2.5 \mathrm{mM}$ NADPH in $150 \mu \mathrm{l}$ of reaction buffer $(0.2 \% \mathrm{BSA}, 5 \mathrm{mM}$ $\mathrm{MgCl} 2,0.1 \mathrm{mM}$ ethoxyresorufin) to the assay wells (Schreiber et al., 2006). The fluorescence was then recorded at Ex 530, Em $585 \mathrm{~nm}$ in 5-10 min intervals over 30 min on a BioTek Synergy $\mathrm{H} 1$ plate reader. A $1 \mathrm{mg} / \mathrm{ml}$ BSA sample was used in duplicate as a blank. A 7-step dilution series of resorufin in methanol was used to generate a standard curve ranging from 0 $800 \mathrm{nM}$. 
Activity of GST was measured as the conjugation of glutathione with 1-chloro-2,4dinitrobenzene (CDNB) by cytosolic protein (Mierzejewski et al., 2014). The total reaction mixture of $250 \mu \mathrm{l}$ contained 0.1 M HEPES buffer ( $\mathrm{pH} 7.6), 1 \mathrm{mM}$ glutathione (GSH), and $25 \mu \mathrm{g}$ of $\mathrm{S} 9$ protein. The reaction was started by adding CDNB (1 $\mathrm{mM}$ final concentration). Formation of the CDNB conjugate was measured by taking absorption readings on a BioTek Synergy $\mathrm{H} 1$ plate reader at $20 \mathrm{~s}$ intervals for $2 \mathrm{~min}$ at $344 \mathrm{~nm}$, and was quantified by using the molar absorptivity of $9.6 \mathrm{mM}-1$ for the enzymatic product.

\section{Statistical analysis}

Biomarker data from field collected fish were analyzed for significant differences between sites within seasons by two-way Analysis of Variance after log10 transformation. In addition, potential seasonal differences were explored by pooling all log transformed data per season, and analyzed with one-way Analysis of Variance. Data from the exposure experiments were also $\log 10$ transformed for one-way Analysis of Variance, followed by Dunnett's post-hoc test to compare treatments with the control. Differences were considered significant when $p<0.05$. Data were analyzed with GraphPad Prism 4.03 (GraphPad, San Diego, CA).

\section{Results:}

\section{Field collected fish}

The bile fluorescence showed a fairly consistent pattern, with minor fluctuations between the sampling locations and between seasons (Figures 2 and 3). Overall average was $69.2^{*} 10^{3}( \pm$ 37.1 S.D.) fluorescence units per $\mu$ l bile for the 2-ring aromatic hydrocarbons, and $4.8^{*} 10^{3}( \pm 2.7$ S.D.) units per $\mu \mathrm{l}$ for the 5-ring compounds. It appears that the Spring samples for the 2-ring compounds may be slightly higher than the other seasons, but statistical analysis to identify any significant differences between sites or seasons could not be performed because of lack of replication; many sampling days had only one or a few fish per site, or none at all (Table 1 Supplemental Information). Even when all sites were pooled to look for seasonal differences, no significant differences were detected. 


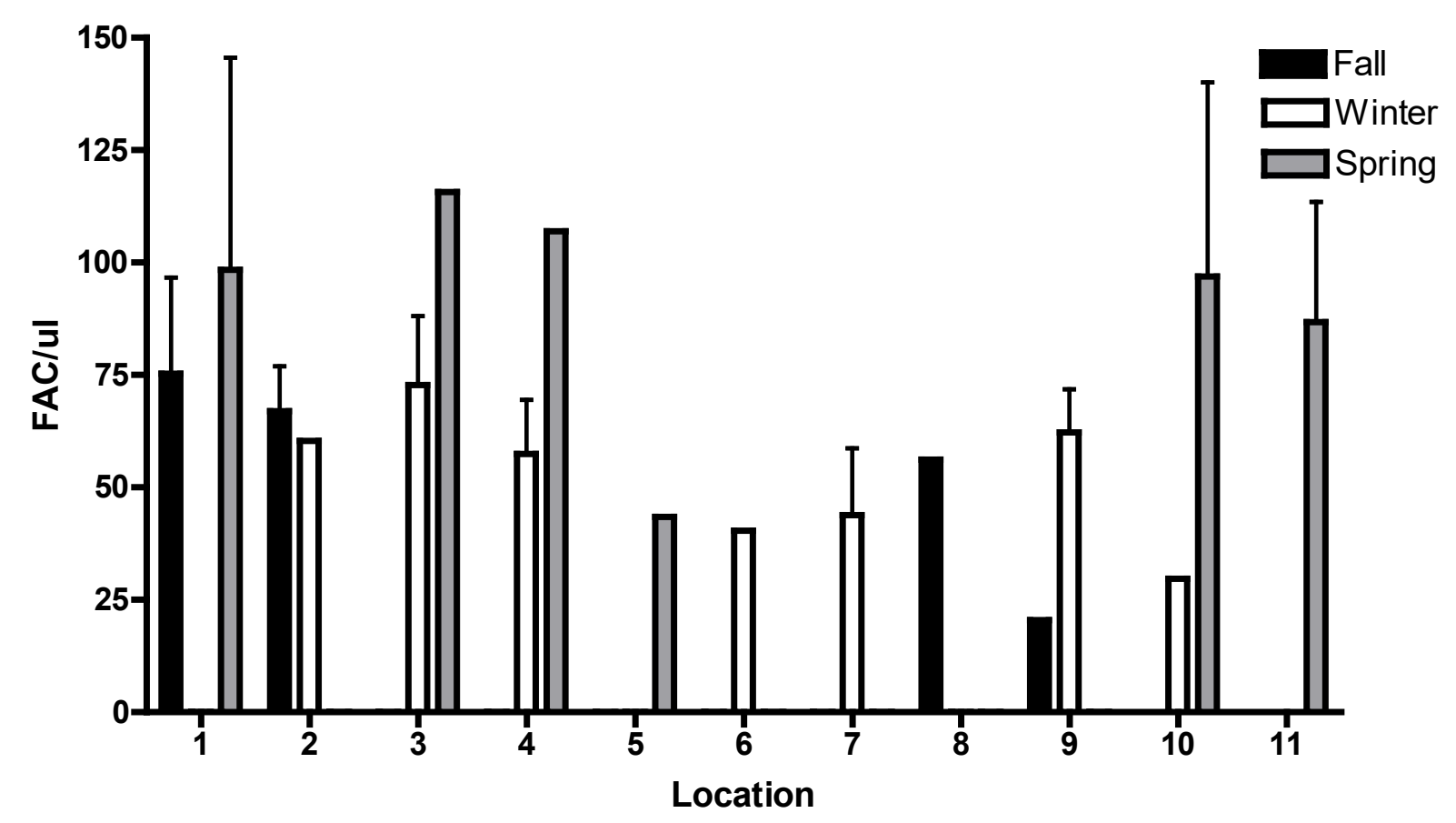

Figure 2. Fluorescence of 2-ring polynuclear aromatic hydrocarbons in bile samples from field collected lionfish in Fall and Winter of 2017 and Spring of 2018. Fluorescent Aromatic Compounds (FAC) in units ${ }^{*} 1000$ per $\mu$ of bile. Sample locations arranged from west to east, according to the map in Figure 1. Average values per site and season, with standard error.

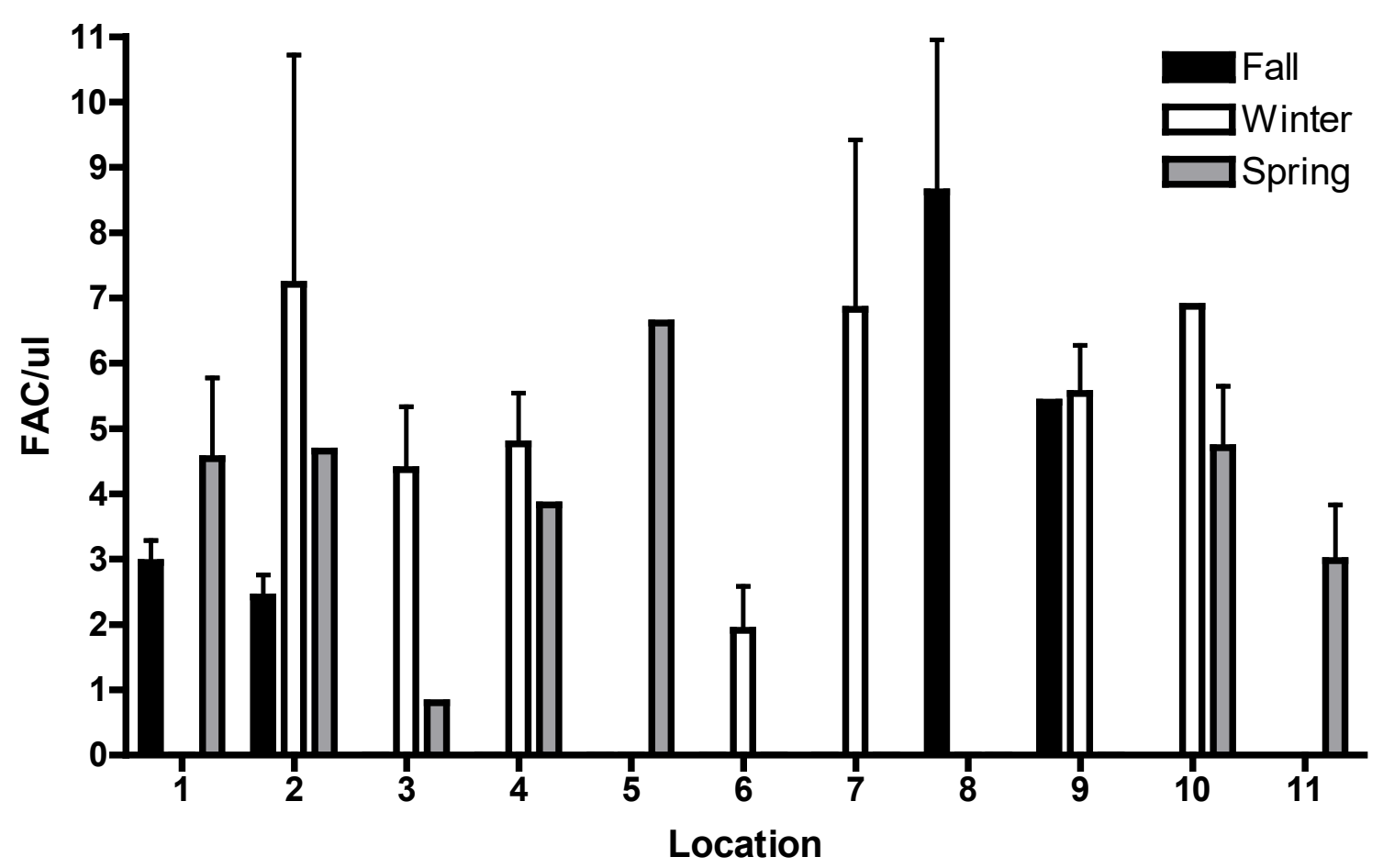


Figure 3. Fluorescence of 5-ring polynuclear aromatic hydrocarbons in bile samples from field collected lionfish in Fall and Winter of 2017 and Spring of 2018. Fluorescent Aromatic Compounds (FAC) in units ${ }^{*} 1000$ per $\mu$ of bile. Sample locations arranged from west to east, according to the map in Figure 1. Average values per site and season, with standard error.

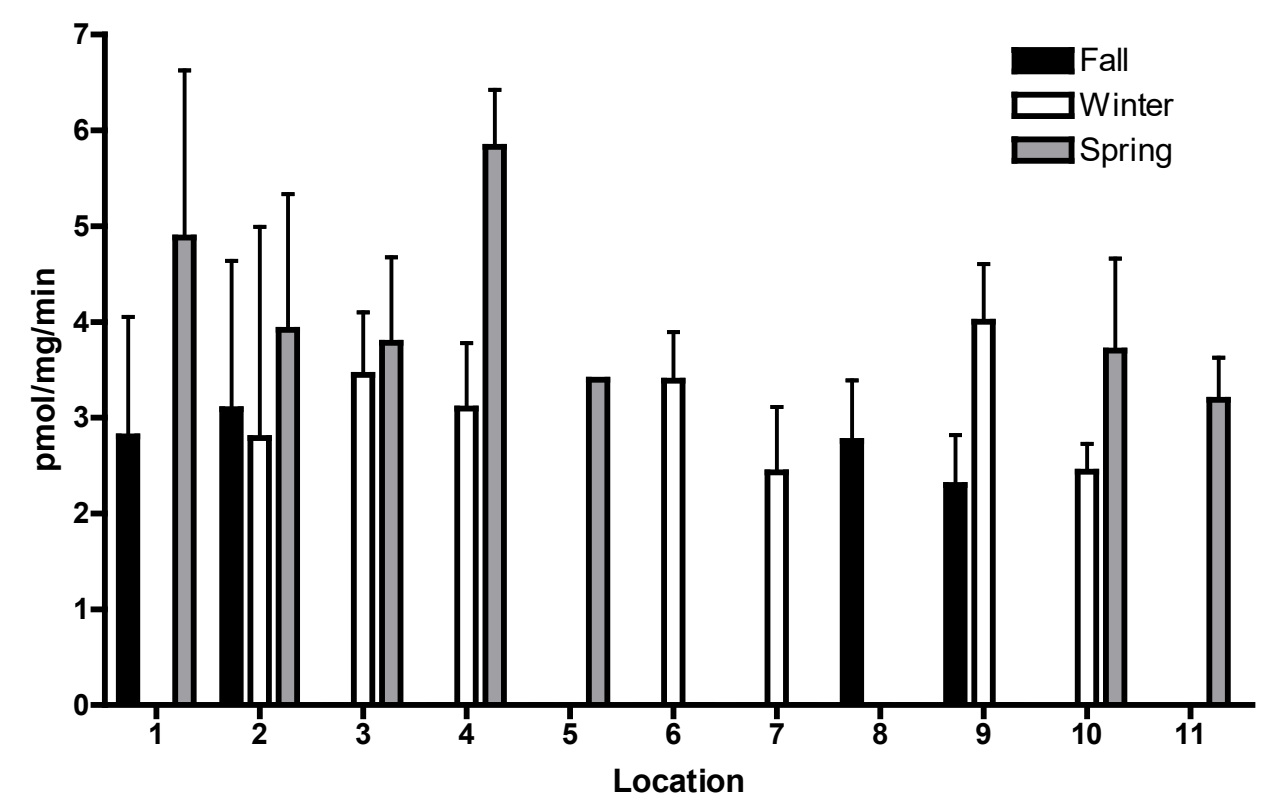

Figure 4. EROD activity in liver tissue from lionfish collected in the Florida Keys in Fall and Winter of 2017 and Spring of 2018. Sample locations arranged from west to east, according to the map in Figure 1. Average values per site and season, with standard error.

As for the bile fluorescence, EROD activity in lionfish livers showed a consistent pattern among sites and seasons (Figure 4). Overall average was $3.42 \mathrm{pmol} / \mathrm{mg} / \mathrm{min}( \pm 1.75$ S.D.), and even though the Spring samples appear to be slightly increased compared to the other seasons, no significant differences were detected between the seasons. 


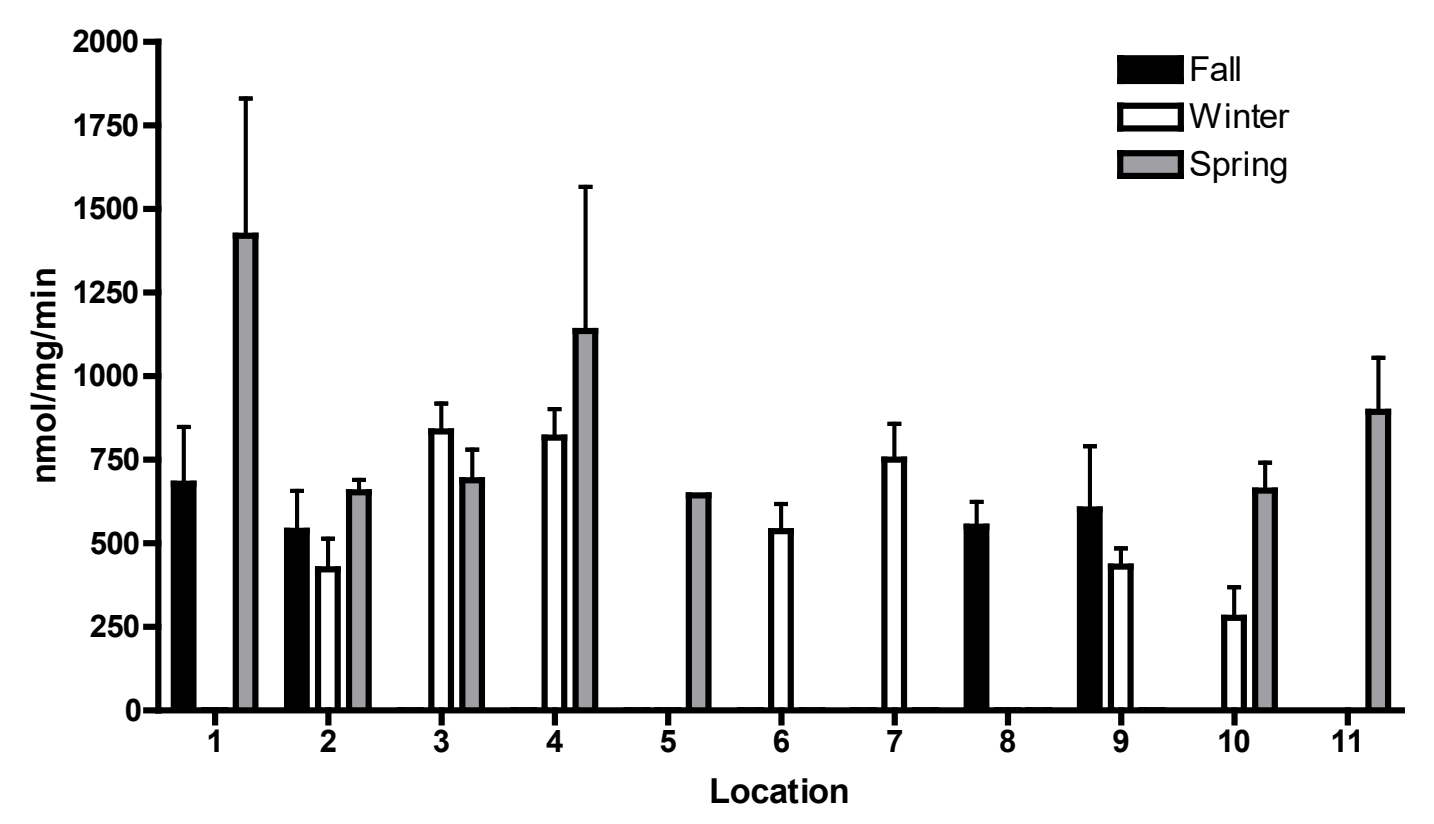

Figure 5. GST activity in liver tissue from lionfish collected in the Florida Keys in Fall and Winter of 2017 and Spring of 2018. Sample locations arranged from west to east, according to the map in Figure 1. Average values per site and season, with standard error.

The GST activity in livers of the collected lionfish were fairly evenly distributed around the overall average of $724 \mathrm{nmol} / \mathrm{mg} / \mathrm{min}$ ( \pm 369 S.D.) (Figure 5). As in the bile fluorescence data, it appears that GST activity in some locations may be elevated, but because of limited sample size for most locations, an analysis of variance could not be performed to confirm any significant differences.

\section{Experimental results}

\section{PAH concentrations:}

The exposure concentrations for the first experiment were based on previous results obtained in exposure experiments with the same HEWAF (DeLorenzo et al., 2018). In those studies, 25\% HEWAF was found to be approximately the $\mathrm{LC}_{50}$ for sheepshead minnow (Cyprinodon variegatus). Not knowing what the expected toxicity of this HEWAF would be for lionfish, it was decided to use 25\% HEWAF as the highest concentration in the first experiment, with two lower exposure concentrations according to a logarithmic sequence in the sublethal range (8.33 and $2.78 \%$ ). Based on the results of this first experiment, a second experiment was set up, for which a lower dose range was selected, with the highest nominal concentration the same as the lowest in the first experiment (2.78\%), followed by log scale dilutions of 0.9 and $0.3 \%$ HEWAF. This resulted in a $\Sigma \mathrm{PAH} 50$ range of $24.7-2727.6 \mu \mathrm{g} / \mathrm{l}$ over both experiments (Table 1 ). Concentrations of individual PAHs and alkylated PAHs in the HEWAF and the tested dilutions are included in the Supplemental Information Tables 2 and 3. Observations from the first experiment suggest that the highest concentration used was close to the $\mathrm{LC}_{50}$ for lionfish, 
because two animals in this treatment group died before the end of the 96h exposure time. Therefore $\mathrm{n}=2$ for the highest concentration in the first experiment.

\begin{tabular}{r|cc} 
\% HEWAF & Experiment 1 & Experiment 2 \\
\hline 100 & 6177.7 & 8563.8 \\
25 & 2727.6 & \\
8.33 & 513.3 & \\
2.78 & 179.0 & 222.1 \\
0.9 & & 90.5 \\
0.3 & & 24.7
\end{tabular}

Table 1. Total PAH concentrations in HEWAF dilutions used for both exposure experiments. $\Sigma$ PAH50 concentrations in $\mu \mathrm{g} / \mathrm{l}$, mean of HEWAFs prepared at $\mathrm{t}=0 \mathrm{~h}$ and $\mathrm{t}=48 \mathrm{~h}$ for each experiment.
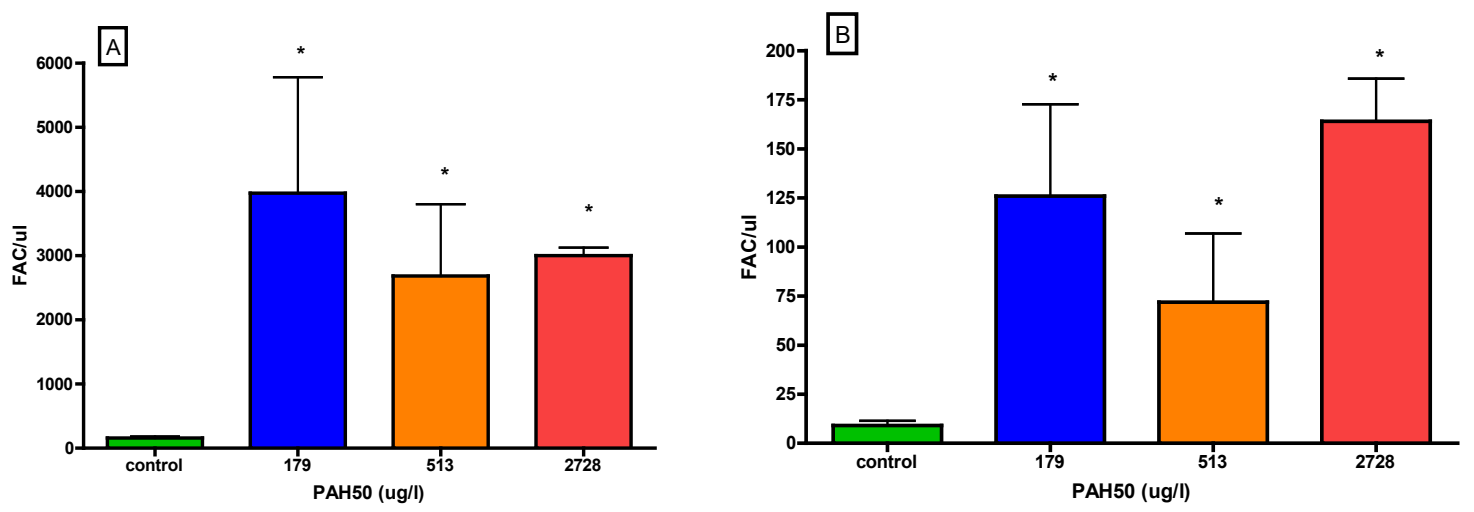

Fig 6. Fluorescence of 2-ring (Panel A) and 5-ring (Panel B) polynuclear aromatic hydrocarbons in bile samples from HEWAF exposed lionfish in experiment 1. Fluorescent Aromatic Compounds (FAC) in units 1000 per $\mu$ l of bile for each treatment group, indicated by actual ¿PAH50 concentration in exposure system. Average values, with standard error. 

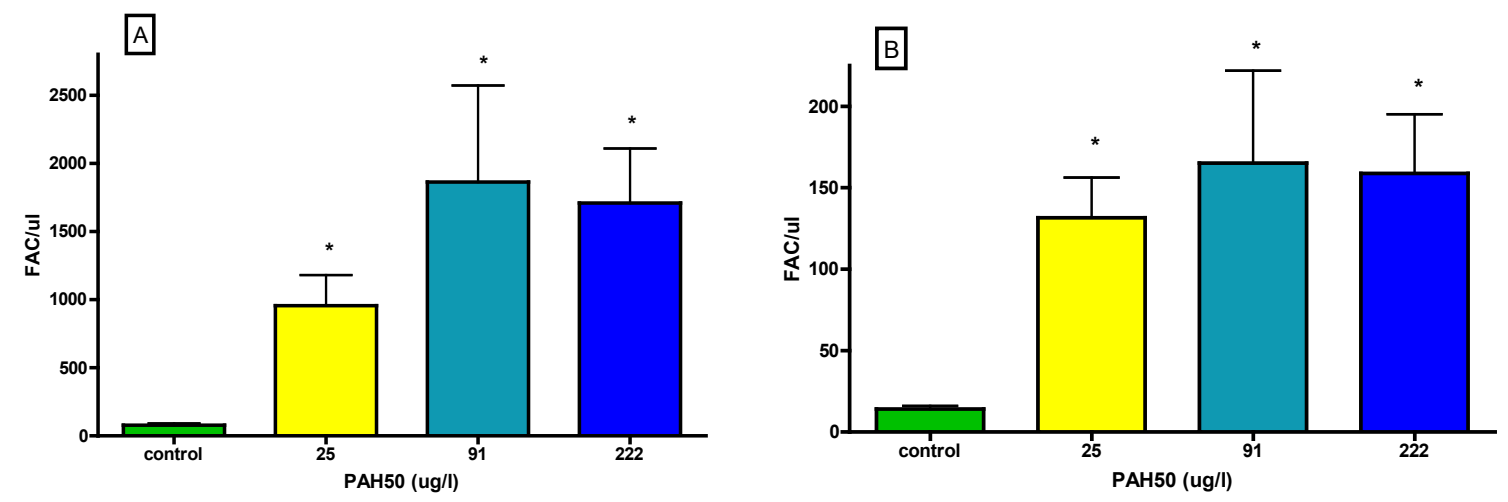

Fig 7. Fluorescence of 2-ring (Panel A) and 5-ring (Panel B) polynuclear aromatic hydrocarbons in bile samples from HEWAF exposed lionfish in experiment 2. Fluorescent Aromatic Compounds (FAC) in units 1000 per $\mu \mathrm{l}$ of bile for each treatment group, indicated by actual $\Sigma$ PAH50 concentration in exposure system. Average values $(n=4$, except $n=2$ for highest concentration in experiment 1 ), with standard error.

After absorption, and potentially metabolism, of PAHs, these fluorescent compounds can be excreted into the bile. Measuring bile fluorescence provides a measure of exposure to PAHs. The fluorescence of multi-ring structures like PAHs is dependent on specific excitation and emission wavelengths. Reported here are the fluorescence units that are specific for 2-ring and 5-ring PAHs. The data from the first experiment showed that for both the 2-ring and the 5-ring PAHs there were highly significant differences between the treated fish and the control fish $(p<$ 0.001 and $p<0.01$ respectively), but no significant differences between the HEWAF exposed treatment groups (Figure 6). This indicates that at the lowest concentration, maximum levels of PAHs were present in the bile. In the second experiment, the pattern of results was the same in that all treatment groups were significantly higher than the control $(p<0.001)$, but there were no significant differences between the treatment groups (Figure 7). Although the fluorescence in the lowest exposure concentration $(26 \mu \mathrm{g} / \mathrm{l})$ was lower than in the higher treatment groups for both the 2-ring and 5-ring PAHs, these differences were not significant.
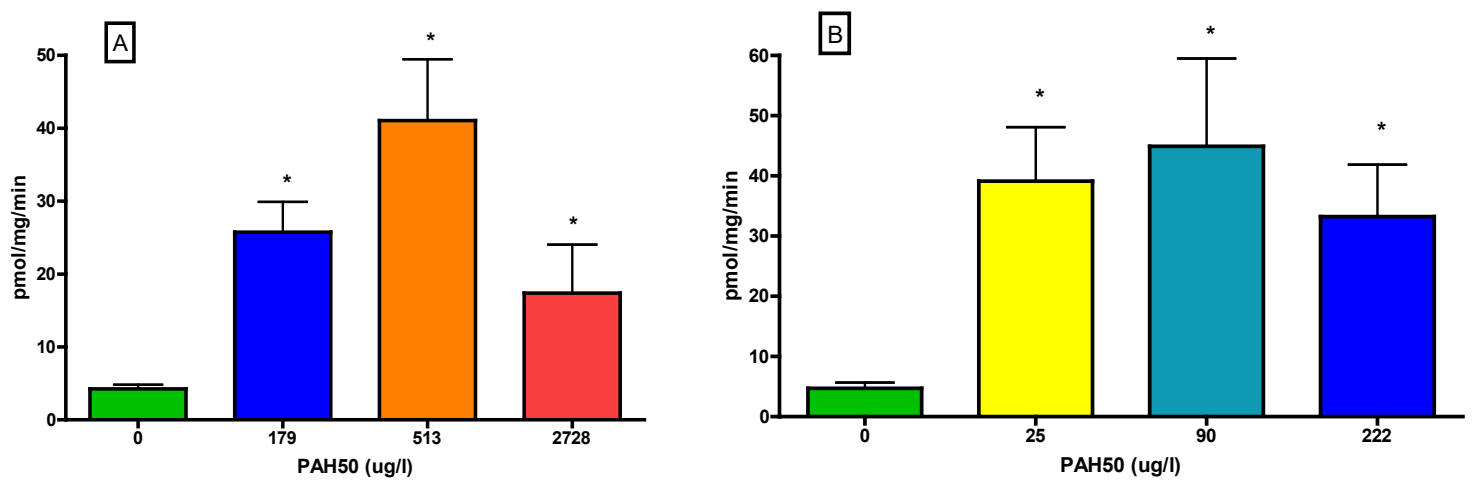

Figure 8. EROD activity in liver homogenates from HEWAF exposed lionfish. Results from Experiment 1 (Panel A) and Experiment 2 (Panel B). EROD activity in pmol/mg/min for each 
treatment group, indicated by actual $\mathrm{PAH} 50$ concentration in exposure system. Average values, with standard error. Asterisks indicate significant differences from the control $(p<0.05)$.

The measured EROD activity in experiment 1 was significantly increased in all treatment groups compared to the control, but there were no significant differences between the exposed treatment groups (Figure 8$)$. The lower activity in the highest treatment $(2728 \mu \mathrm{g} / \mathrm{l})$ may be a result of the morbidity in these animals, as two animals in this treatment died prematurely. Therefore, $n=2$ in this treatment. In the second experiment, with lower exposure concentrations, again all treatment groups had significantly higher EROD activity than the control, up to 10 times higher, but no significant differences were observed between the treatment groups. It is noteworthy that even at the lowest exposure concentration of $25 \mu \mathrm{g} / \mathrm{\Sigma} \mathrm{PAH} 50$ there was a maximum induction of EROD activity.
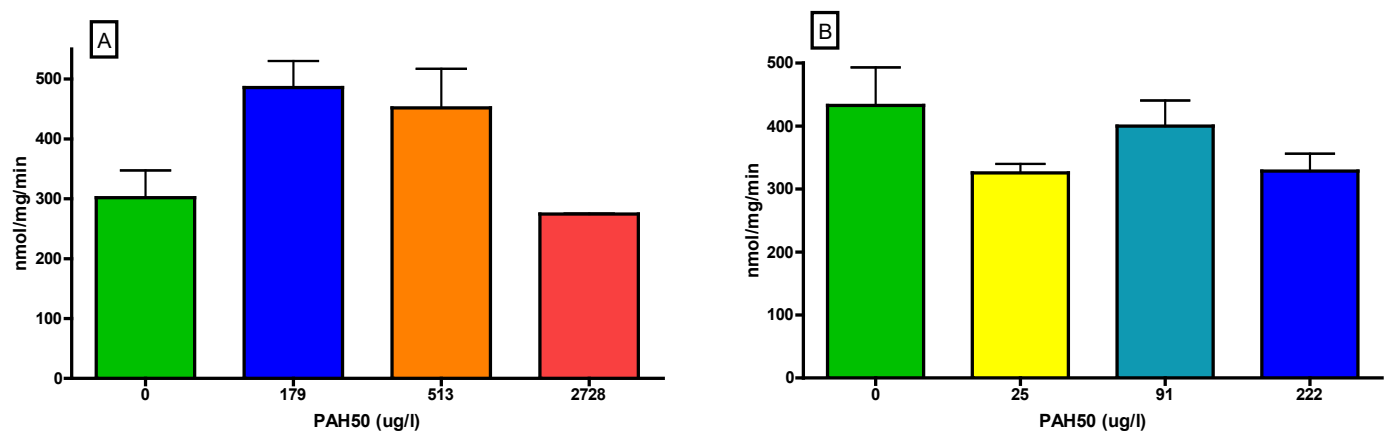

Figure 9. GST activity in liver homogenates from HEWAF exposed lionfish. Results from Experiment 1 (Panel A) and Experiment 2 (Panel B). GST activity in $\mathrm{nmol} / \mathrm{mg} / \mathrm{min}$ for each treatment group, indicated by actual $\mathrm{PAH} 50$ concentration in exposure system. Average values with standard error.

The measured GST activity in the HEWAF exposed fish was not significantly different from the control in either one of the experiments (Figure 9). The lower activity in the highest treatment group of experiment 1 may be a result of morbidity in these fish, as was seen in the EROD activity in these fish.

\section{Discussion and conclusions:}

The goals of this study were to investigate if lionfish could be used as biomonitoring species for oil spills in coral reef ecosystems, and specifically if oil and diesel fuel that leaked from boats that were sunk when hurricane Irma hit the Florida Keys in August 2017 had an effect on lionfish in that area. Fish were captured in an area south of Marathon Key within a few weeks after the hurricane came through, but the results did not show any overall differences for the biomarkers measured when compared with fish that were collected several months later in December 2017 or March 2018. 
While there could be a variety of reasons that no significant differences were found between the seasons or between the sites, it was unknown if the biomarkers that were measured are actually responsive in lionfish when they are exposed to mineral oil compounds. We therefore set up experiments in which lionfish were exposed to a seawater extract of Louisiana crude oil. The results of these experiments showed that lionfish do absorb the oil related PAHs and excrete them into the bile, as measured through the bile fluorescence biomarker. This biomarker has found widespread application, and is considered a reliable indicator of exposure to PAHs (Beyer et al., 2010; Kamann et al., 2017).

As a result of the experimental oil exposure, an increase in cytochrome P450-1A was observed, as measured through the EROD assay, which is an indicator for the cytochrome P450 isoform that is specific for aromatic hydrocarbons. Even at the lowest $\Sigma$ PAH50 concentration of $25 \mu \mathrm{g} / \mathrm{l} \mathrm{a}$ 10 times induction over the control was measured, which has been observed for other species as well (Whyte et al., 2000; Schlenk et al., 2008). Follow up studies could be performed at even lower concentrations to obtain a classical dose-response curve. However, for the proof of concept purpose of this study the near maximum EROD response observed at $25 \mu \mathrm{g} / \mathrm{l}$, which corresponds to $3 \mathrm{mg} / \mathrm{l}$ of crude oil, indicates that increased EROD activity in lionfish should be expected in field situations where fish were recently exposed to oil spills. Environmental concentrations of PAHs around oil spills are highly variable because of rapid dispersion and differential fate of different groups of PAHs, but concentrations of up to $65.8 \mu \mathrm{g} / \mathrm{l}$ of total hydrocarbons were measured in plumes associated with the Deepwater Horizon oil spill (Spier et al., 2013).

The GST activity in lionfish was not significantly changed as a result of exposure to the HEWAF. The assay used to measure GST activity is not specific for individual GST isoforms, but more a general indicator for overall GST activity. Nevertheless, some have found that overall GST activity can be induced as a result of oil exposure (Kerambrun et al., 2012; Nahrgang et al., 2010); but others have argued that the GST biomarker is very species specific (Smeltz et al., 2017; van den Hurk et al., 2017). Because the overall GST activity, as measured with the CDNB assay, is not specific for individual GST isoforms, effects on a lesser expressed isoforms may be masked by more abundant, non-responsive isoforms in selected species.

Comparing the results of the field collected fish with data from the exposure experiments demonstrated that all the measured biomarkers in the field collected fish fall within the normal background range. The exposure experiments showed that when lionfish are exposed to oil compounds, a significant increase in bile fluorescence and EROD activity can be expected. Because these increases were not observed in the field collected fish, it is concluded that they were not exposed to oil compounds in the period before the first sampling period.

The opportunity to sample soon after an oil spill or other environmental disaster may be hampered by logistic constraints. The passage of hurricane Irma through the Florida Keys created a major disruption of infrastructure and loss of property (https://www.monroecountyfl.gov/726/Hurricane-Irma-Recovery), and thanks to generous support by local concerned residents, we were able to collect lionfish at several locations south of Marathon, FL, only four 
weeks after the hurricane had passed through the area. The fact that we didn't observe any toxicological effects in the lionfish that were collected at that point could be attributed to the time period that had passed between the disaster, and its associated oil and fuel spills, and the measurements of biomarkers in fish. However, several studies, reviewed in Lee and Anderson (2005), showed that cytochrome P450-1A activities may be elevated up to four months, or longer, in fish exposed to oil compounds. This would indicate that if the lionfish in our research area were exposed to significant amounts of oil, an increased EROD activity was to be expected. However, depending on the composition of the oil, as was demonstrated after the Deepwater Horizon spill, the environmental fate of oil compounds in the marine environment can be quite unpredictable. Smaller, more volatile compounds evaporate or are metabolized by microorganisms, while the heavier compounds form tar balls and end up in coastal sediments (Mulabagal et al., 2013). Based on our results for both the bile fluorescence and EROD induction it can be assumed that the reef systems south of Marathon, FL, were not impacted by oil and fuel leaks originating from sunken ships in the surrounding marinas, and that the lack of a response is not due to a potential four week recovery period between the occurrence of the hurricane and the first sampling period.

The exposure experiments clearly demonstrated that lionfish are sensitive to oil pollution, and biomarkers like bile fluorescence and EROD activity are responsive to oil exposure in this species. Very few studies have been published on the ecotoxicology of lionfish, including studies on the accumulation of mercury, and the effects of the pesticide chlordecone (Huge et al., 2014; Ritger et al., 2018; Charlotte et al., 2016). Some locations in the study by Ritger et al. (2018) were close to a large petroleum refinery on the island of Curaçao, which could be a source of PAHs. But no information on potential oil or PAH effects were reported, and further inquiry with the authors did not reveal any additional observations in lionfish of effects that could be attributed to exposure to oil compounds. In a recent study by Horricks et al. (2019) results are reported that indicate that lionfish are bioaccumulating residues of ultraviolet filters that are commonly used in sunscreen lotions, and that lionfish may therefore be a useful sentinel species for monitoring these organic ultraviolet filters in the Caribbean Sea.

The 2010 Deepwater Horizon oil spill released millions of gallons of crude oil into the Gulf of Mexico (Beyer et al., 2016). To assess the ecotoxicological effects of this spill, a large number of studies were undertaken to measure the effects of spilled oil on different life forms in the Gulf of Mexico. In a recent publication, a summary of the $50+$ fish studies published so far were reviewed (Pasparakis et al., 2019), but only one study reported the effects on reef fish (Johansen et al, 2017). In this study, larvae of Chromis, Pomacentrus, and Lethrinus were exposed to oil and monitored for behavioral impairments, but no information on potential effects in lionfish or related species were reported.

Based on the results from this study it can be concluded that lionfish is a suitable species for monitoring the ecotoxicological effects of oil pollution incidents. Future research into the responses of this species to other mixtures of PAHs than HEWAFs, as found for instance in diesel fuel, should further support the preliminary results obtained in this study. A benefit of using this species in future impact assessments is the widespread occurrence in the Caribbean, 
Gulf of Mexico and western Atlantic coastal zone. Because this is an invasive species there are no restrictions on capturing lionfish, and their relatively slow swimming speed, easy recognition, and tendency to linger among coral reef structures makes them easy to collect (Chaves et al., 2016). This opens up the possibility for involving SCUBA divers as citizen scientists and have them assist in collecting sufficient numbers of animals per location. Numerous lionfish derby events are organized on a regular basis throughout the newly established range in the Western hemisphere; which would expand possibilities for citizen scientists to be involved in monitoring oil spill events beyond the already established network of commercial fishermen and fishing communities (Sullivan et al., 2018).

\section{Acknowledgements:}

We are indebted to the Guevara and Edhlund families for their support of the field collections in the Florida Keys. Thanks go out to Clemson University SCUBA divers who helped collect the lionfish; Pete Key, Paul Pennington, Blaine West, and James Daugomah at NOAA-NOS in Charleston, SC for help with performing the exposure experiments, and the Clemson University Creative Inquiry program for financial support.

The scientific results and conclusions, as well as any opinions expressed herein, are those of the author(s) and do not necessarily reflect the views of NOAA or the Department of Commerce. The mention of any commercial product is not meant as an endorsement by the Agency or Department.

\section{References:}

Ateweberhan M, Feary DA, Keshavmurthy S, Chen A, Schleyer MH, Sheppard CR. (2013) Climate change impacts on coral reefs: synergies with local effects, possibilities for acclimation, and management implications. Mar Pollut Bull 74(2):526-39

Beyer J, Jonsson G, Porte C, Krahn MM, Ariese F. (2010) Analytical methods for determining metabolites of polycyclic aromatic hydrocarbon (PAH) pollutants in fish bile: A review. Environ Toxicol Pharmacol. 2010 Nov;30(3):224-44

Beyer J, Trannum HC, Bakke T, Hodson PV, Collier TK. (2016) Environmental effects of the Deepwater Horizon oil spill: A review. Mar Pollut Bull 110(1):28-51

Bors EK, Herrera S, Morris JA, Shank TM. (2019) Population genomics of rapidly invading lionfish in the Caribbean reveals signals of range expansion in the absence of spatial population structure. Ecol Evol. 9(6):3306-3320 
Charlotte DR, Yolande BN, Cordonnier S, Claude B. (2016) The invasive lionfish, Pterois volitans, used as a sentinel species to assess the organochlorine pollution by chlordecone in Guadeloupe (Lesser Antilles). Mar Pollut Bull. 107(1):102-106

Chaves LC, Hall J, Feitosa JL, Côté IM. (2016) Photo-identification as a simple tool for studying invasive lionfish Pterois volitans populations. J Fish Biol 88(2):800-4

DeLorenzo ME, Key PB, Chung KW, Pisarski E, Shaddrix B, Wirth EF, Pennington PL, Wade J, Franco M, Fulton MH. (2018) Comparative Toxicity of Two Chemical Dispersants and Dispersed Oil in Estuarine Organisms. Arch Environ Contam Toxicol. 2018 Apr;74(3):414-430

Futch JC, Griffin DW, Lipp EK. (2010) Human enteric viruses in groundwater indicate offshore transport of human sewage to coral reefs of the Upper Florida Keys. Environ Microbiol. 12(4):964-74

Hackerott S, Valdivia A, Cox CE, Silbiger NJ, Bruno JF. (2017) Invasive lionfish had no measurable effect on prey fish community structure across the Belizean Barrier Reef. PeerJ. 5:e3270

Horricks RA, Tabin SK, Edwards JJ, Lumsden JS, Marancik DP. (2019) Organic ultraviolet filters in nearshore waters and in the invasive lionfish (Pterois volitans) in Grenada, West Indies. PLoS One. 14(7):e0220280

Huge DH, Schofield PJ, Jacoby CA, Frazer TK. (2014) Total mercury concentrations in lionfish (Pterois volitans/miles) from the Florida Keys National Marine Sanctuary, USA. Mar Pollut Bull. 78(1-2):51-5

Johansen JL, Allan BJM, Rummer JL, Esbaugh AJ. (2017) Oil exposure disrupts early lifehistory stages of coral reef fishes via behavioural impairments.Nat Ecol Evol. 2017 Aug;1(8):1146-1152. doi: 10.1038/s41559-017-0232-5. Epub 2017 Jul 17. Erratum in: Nat Ecol Evol. 2017 Sep;1(9):1412.

Kammann U, Akcha F, Budzinski H, Burgeot T, Gubbins MJ, Lang T, Le Menach K, Vethaak AD, Hylland K. (2017) PAH metabolites in fish bile: From the Seine estuary to Iceland. Mar Environ Res.124:41-45

Kemp KM, Westrich JR, Alabady MS, Edwards ML, Lipp EK. (2018) Abundance and Multilocus Sequence Analysis of Vibrio Bacteria Associated with Diseased Elkhorn Coral (Acropora palmata) of the Florida Keys. Appl Environ Microbiol. 84(2). pii: e01035-17

Kerambrun E, Le Floch S, Sanchez W, Thomas Guyon H, Meziane T, Henry F, Amara R. (2012) Responses of juvenile sea bass, Dicentrarchus labrax, exposed to acute concentrations of crude oil, as assessed by molecular and physiological biomarkers. Chemosphere 87(7):692702 
Lee RF, Anderson JW. (2005) Significance of cytochrome P450 system responses and levels of bile fluorescent aromatic compounds in marine wildlife following oil spills. Mar Pollut Bull. 50(7):705-23

Mierzejewski J, Haney DC, van den Hurk P. (2014) Biomarker responses in sunfish species and largemouth bass from the Saluda River, South Carolina. Ecotoxicol Environ Saf. 2014 Dec;110:8-15

Mulabagal V, Yin F, John GF, Hayworth JS, Clement TP. (2013) Chemical fingerprinting of petroleum biomarkers in Deepwater Horizon oil spill samples collected from Alabama shoreline. Mar Pollut Bull 70(1-2):147-54

Nahrgang J, Camus L, Gonzalez P, Jönsson M, Christiansen JS, Hop H. (2010) Biomarker responses in polar cod (Boreogadus saida) exposed to dietary crude oil. Aquat Toxicol. 2010 Jan 21;96(1):77-83

Pasparakis C, Esbaugh AJ, Burggren W, Grosell M. (2019) Impacts of deepwater horizon oil on fish.Comp Biochem Physiol C Toxicol Pharmacol. 224:108558. doi: 10.1016/j.cbpc.2019.06.002

Ritger AL, Curtis AN, Chen CY. (2018) Bioaccumulation of mercury and other metal contaminants in invasive lionfish (Pterois volitans/miles) from Curaçao. Mar Pollut Bull. 131(Pt A):38-44

Schlenk D, Celander M, Gallagher E, George S, James M, Kullman S, Van den Hurk P, Willett K. (2008). Biotransformation in Fishes. In: Toxicology of fishes. D. Hinton, R. DiGiulio (eds). CRC Press, Boca Raton, FI. pp 153-234

Schreiber EA, Otter RR, Van den Hurk P. (2006) A biomarker approach to measure biological effects of contaminant exposure in largemouth bass from Lake Conestee, South Carolina, U.S.A. Environ Toxicol Chem 25(7):1926-32

Smeltz M, Rowland-Faux L, Ghiran C, Patterson WF 3rd, Garner SB, Beers A, Mièvre Q, Kane AS, James MO. (2017) A multi-year study of hepatic biomarkers in coastal fishes from the Gulf of Mexico after the Deepwater Horizon Oil Spill. Mar Environ Res 129:57-67

Spier C, Stringfellow WT, Hazen TC, Conrad M. (2013) Distribution of hydrocarbons released during the 2010 MC252 oil spill in deep offshore waters. Environ Pollut. 173:224-30

Sullivan J, Croisant S, Howarth M, Rowe GT, Fernando H, Phillips-Savoy A, Jackson D, Prochaska J, Ansari GAS, Penning TM, Elferink C; Community Partner Authors: Louisiana Environmental Action Network, United Houma Nation, Bayou Interfaith Shared Community Organizing, Dustin Nguyen-Vietnamese Community Partner, Center for Environmental \& Economic Justice, and Alabama Fisheries CooperativeProject Community Scientist Author: 
Wilma Subra. (2018) Building and Maintaining a Citizen Science Network With Fishermen and Fishing Communities Post Deepwater Horizon Oil Disaster Using a CBPR Approach. New Solut. 28(3):416-447

Toth LT, Stathakopoulos A, Kuffner IB, Ruzicka RR, Collela MA, Shinn EA. (2019) The unprecedented loss of Florida's reef-building corals and the emergence of a novel coral-reef assemblage. Ecology e02781. doi: 10.1002/ecy.2781

Turner NR, Renegar DA. (2017) Petroleum hydrocarbon toxicity to corals: A review. Mar Pollut Bull. 119(2):1-16

Usseglio P, Selwyn JD, Downey-Wall AM, Hogan JD. (2017) Effectiveness of removals of the invasive lionfish: how many dives are needed to deplete a reef? PeerJ. 5:e3043

van den Hurk P, Gerzel LE, Calomiris P, Haney DC. (2017) Phylogenetic signals in detoxification pathways in Cyprinid and Centrarchid species in relation to sensitivity to environmental pollutants. Aquat Toxicol. 188:20-25

van den Hurk P. (2006) Bile fluorescence, heme oxygenase induction, and increased biliverdin excretion by mixtures of environmental toxicants. Aquat Toxicol. 77(2):202-9

van der Oost R, Beyer J, Vermeulen NP. (2003) Fish bioaccumulation and biomarkers in environmental risk assessment: a review. Environ Toxicol Pharmacol. 2003 Feb;13(2):57-149

Whyte JJ, Jung RE, Schmitt CJ, Tillitt DE. (2000) Ethoxyresorufin-O-deethylase (EROD) activity in fish as a biomarker of chemical exposure. Crit Rev Toxicol. 2000 Jul;30(4):347-570. Review

\section{Supplemental information:}

Supplemental Table 1. Sampling locations with depth and geographical coordinates, number of fish collected per season, and size range of collected fish ( $\mathrm{mm}$ ).

\begin{tabular}{|l|l|l|l|l|l|l|l|}
\hline Site & Depth & Latitude & Longitude & Fall $(\mathrm{n})$ & $\begin{array}{l}\text { Winter } \\
(\mathrm{n})\end{array}$ & $\begin{array}{l}\text { Spring } \\
(\mathrm{n})\end{array}$ & $\begin{array}{l}\text { Size Range } \\
(\mathrm{mm})\end{array}$ \\
\hline 50 live & 50 & 24.709733 & -80.856867 & 3 & 6 & 0 & $195-252$ \\
\hline Cannon & 20 & 24.723100 & -80.861733 & 2 & 0 & 0 & $187-206$ \\
\hline Delta Shoal & 20 & 24.631983 & -81.090567 & 2 & 0 & 3 & $125-300$ \\
\hline
\end{tabular}




\begin{tabular}{|l|l|l|l|l|l|l|l|}
\hline Grouper Trail & 60 & 24.684783 & -80.921867 & 0 & 7 & 7 & $115-240$ \\
\hline Kissing Grunts & 30 & 24.687217 & -80.924150 & 0 & 4 & 4 & $115-250$ \\
\hline Long Key Ledge & 30 & 24.717930 & -80.844680 & 0 & 1 & 5 & $110-220$ \\
\hline Lost n Found & 30 & 24.709367 & -80.870100 & 0 & 7 & 0 & $87-255$ \\
\hline Porkfish & 30 & 24.700500 & -80.893150 & 0 & 4 & 0 & $205-250$ \\
\hline Thunderbolt & 115 & 24.661200 & -80.963283 & 2 & 2 & 2 & $131-276$ \\
\hline Deep Drop & 65 & 24.732090 & -80.790810 & 0 & 0 & 8 & $120-280$ \\
\hline $\begin{array}{l}\text { West Turtle } \\
\text { Shoals }\end{array}$ & 18 & 24.720450 & -80.927500 & 0 & 0 & 5 & $110-245$ \\
\hline
\end{tabular}

Based on Wilcox et al. (2018) we assumed that all fish belonged to the same species continuum, and did not attempt to make distinctions between $P$. volitans and $P$. miles. Population structure analysis showed that one year old lionfish are around $150 \mathrm{~mm}$, and because this species rarely gets older than 3 year old, all larger individuals are mostly 2 year old (Johnson and Swenarton, 2016). Gender could not be established for the fish because they were collected outside the spawning season, and therefore the gonads were inconspicuous. Secondary sex characteristics that could have facilitated gender determination were not observed in the collected fish.

Johnson EG, Swenarton MK. Age, growth and population structure of invasive lionfish (Pterois volitans/miles) in northeast Florida using a length-based, age-structured population model.

PeerJ. 2016 Dec 1;4:e2730

Wilcox CL, Motomura H, Matsunuma M, Bowen BW. Phylogeography of Lionfishes (Pterois) Indicate Taxonomic Over Splitting and Hybrid Origin of the Invasive Pterois volitans. J Hered. 2018 Feb 14;109(2):162-175

Supplemental Table 2. PAH concentrations in 100\% HEWAF, and tested dilutions in Experiment 1 , at beginning of exposure $(\mathrm{t}=0)$ and after 48 hours $(\mathrm{t}=48)$. All units in $\mu \mathrm{g} / \mathrm{L}$.

Chemical

1,2-Dimethylnaphthalene

1,3+1,6-Dimethylnaphthalene

1,4,6- and 2,3,6-Trimethylnaphthalene

1,4-Dimethylnaphthalene

\begin{tabular}{|c|c|c|c|c|c|c|c|}
\hline & $100 x$ & & & $8.3 x$ & & $2.7 x$ & \\
\hline $100 x$ t0 & $48 \mathrm{~h}$ & $25 x$ t0 & $8.3 x$ t0 & $48 \mathrm{~h}$ & $2.7 x$ t0 & $48 \mathrm{~h}$ & $0 x$ t0 \\
\hline 65.475 & 35.981 & 14.5305 & 1.246 & 2.98333 & 1.5663 & 0.9528 & 0.01801 \\
\hline 644.915 & 373.978 & 147.545 & 13.8028 & 31.1883 & 16.3731 & 10.7899 & 0.08339 \\
\hline 258.916 & 163.874 & 197.47 & 21.3968 & 14.8493 & 7.4395 & 4.449 & 0.08521 \\
\hline 82.913 & 49.31 & 21.4978 & 1.53083 & 3.70033 & 2.1458 & 1.5069 & 0.04438 \\
\hline
\end{tabular}




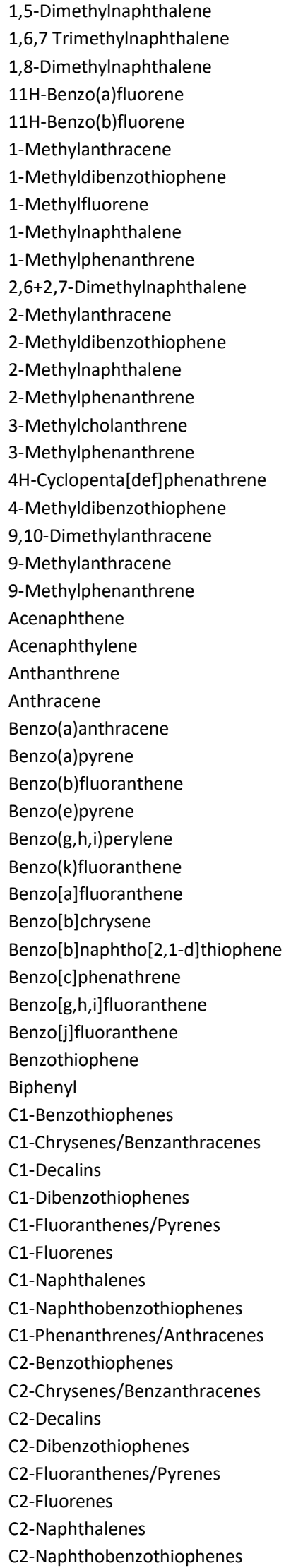

\begin{tabular}{|c|c|c|c|c|c|c|c|}
\hline 85.779 & 49.834 & 19.9225 & 1.70183 & 3.99283 & 2.1622 & 1.412 & 0.01377 \\
\hline 17.425 & 148.59 & 198.55 & 18.3923 & 11.63 & 6.1285 & 4.007 & 0.05042 \\
\hline 47.69 & 25.018 & 11.527 & 1.28467 & 0.58263 & 0.2503 & 0.2503 & 0.2503 \\
\hline 3.359 & 2.076 & 1.0425 & 0.29567 & 0.17683 & 0.1144 & 0.0635 & 0.01497 \\
\hline 11.831 & 9.043 & 3.34175 & 1.19983 & 0.74867 & 0.4559 & 0.2636 & 0.01993 \\
\hline 4.92 & 3.729 & 1.38025 & 0.478 & 0.27283 & 0.1311 & 0.1248 & 0.00928 \\
\hline 9.541 & 5.82 & 2.724 & 0.92183 & 0.84 & 0.0889 & 0.1826 & 0.00655 \\
\hline 113.071 & 81.128 & 30.6433 & 10.3428 & 13.7543 & 3.4739 & 2.2059 & 0.01044 \\
\hline 273.385 & 264.532 & 83.5343 & 26.9375 & 16.6403 & 12.3353 & 7.7184 & 0.14038 \\
\hline 73.358 & 48.037 & 19.7655 & 6.61317 & 4.41417 & 2.2085 & 1.5212 & 0.01175 \\
\hline 179.944 & 155.945 & 63.2415 & 17.446 & 15.4138 & 6.9251 & 3.6658 & 0.05242 \\
\hline 6.648 & 0.02896 & 2.05075 & 0.76783 & 0.0051 & 0.00942 & 0.00285 & 0.01306 \\
\hline 7.202 & 4.545 & 2.114 & 0.72533 & 0.61717 & 0.0684 & 0.1594 & 0.01434 \\
\hline 489.629 & 365.143 & 126.863 & 40.5025 & 27.5885 & 17.115 & 10.048 & 0.2169 \\
\hline 107.011 & 74.223 & 28.3285 & 9.69933 & 5.00733 & 4682 & 2.3477 & 0.02033 \\
\hline 0.69763 & 0.20246 & 0.16411 & 0.11283 & 0.08074 & 0.04156 & 0.01519 & 0.05576 \\
\hline 103.138 & 67.87 & 27.528 & 9.1185 & 5.65367 & 0054 & 014 & 0757 \\
\hline 0.0285 & 0.02803 & 0.02004 & 0.01896 & 0.00496 & 0.00901 & 0.00274 & 0.00929 \\
\hline 28.646 & 17.942 & 8.12675 & 2.7 & 1.918 & 604 & 371 & 0677 \\
\hline 0.07276 & 0.07158 & 0.05116 & 0.04841 & 0.01266 & 0.023 & 0.00699 & 0.02371 \\
\hline 0.03194 & 0.03209 & 0.02271 & $0 . c$ & 65 & 44 & 16 & 447 \\
\hline 101.471 & 64.968 & 27.0108 & 8.88167 & 5.90383 & 2.9352 & 1.9607 & 0.01141 \\
\hline 0.24769 & 0.25854 & 0.05593 & 66 & 279 & 077 & 0.02148 & 0.02736 \\
\hline 15.3 & 9.374 & 4.0775 & 1.60267 & 0.92783 & 0.4105 & 0.2778 & 0.00521 \\
\hline 0.55009 & 0.17856 & 0.13743 & 0.0717 & 0.0601 & 0.03128 & 0.0132 & 0.03752 \\
\hline 0.02156 & 0.02121 & 0.01516 & 0.01434 & 0.00375 & 0.00682 & 0.00207 & 0.00703 \\
\hline 2.901 & 1.658 & 0.8 & & & & 552 & 635 \\
\hline 0.576 & 0.315 & 0.16075 & 0.02403 & 0.04712 & 0.02369 & 0.016 & 0.02806 \\
\hline 1.5 & 1.198 & 0.421 & 0.2125 & 0.11017 & 0.0469 & 0.0441 & 0.01649 \\
\hline 2.665 & 1.75 & 0.72575 & 0.21483 & 0.16667 & 0.0785 & 0.0544 & 0.01328 \\
\hline 0.435 & 0.298 & 0.13625 & 0.03633 & 0.01812 & 0.00943 & 0.005 & 0.01131 \\
\hline 0.19068 & 0.05339 & 0.04989 & 0.01278 & 0.02319 & 0.01149 & 0.005 & 0.01469 \\
\hline 0.24801 & 0.06944 & 0.06489 & 0.01662 & 0.03017 & 0.01495 & 0.00565 & 0.01911 \\
\hline 0.2482 & 0.08062 & 0.06201 & 0.03236 & 0.02712 & 0.01412 & 0.00596 & 0.01693 \\
\hline 2.82 & 1.682 & 0.8 & 0.26167 & 0.16517 & 0.0842 & 0.0527 & 0.00464 \\
\hline 1.097 & 0.746 & 0.363 & 0.10833 & 0.08383 & 0.05 & 0.0304 & 0.00496 \\
\hline 0.01596 & 0.01412 & 0.01038 & 0.00989 & 0.00782 & 0.00441 & 0.00134 & 0.00582 \\
\hline 0.24598 & 0.06887 & 0.06436 & 0.01649 & 0.02992 & 0.01482 & 0.0056 & 0.01896 \\
\hline 0.08433 & 0.06202 & 0.01368 & 0.01171 & 0.03658 & 0.00739 & 0.00512 & 0.00721 \\
\hline 71.93 & 51.899 & 20.3973 & 6.193 & 4.812 & 2.4515 & 1.5331 & 0.0045 \\
\hline 48.269 & 19.366 & 8.6145 & 2.68933 & 2.2965 & 0.7895 & 0.6825 & 0.01586 \\
\hline 18.436 & 11.567 & 4.55775 & 1.78333 & 0.97833 & 0.5879 & 0.3698 & 0.0164 \\
\hline 517.505 & 558.839 & 154.268 & 24.2297 & 135.855 & 13.0586 & 11.2507 & 0.10588 \\
\hline 57.302 & 36.672 & 16.8288 & 5.8085 & 4.89683 & 0.4997 & 1.0731 & 0.01393 \\
\hline 9.635 & 6.131 & 2.4005 & 0.978 & 0.50633 & 0.4032 & 0.223 & 0.02413 \\
\hline 286.471 & 183.378 & 76.6793 & 23.7957 & 45.7147 & 7.7807 & 4.6009 & 0.01076 \\
\hline 778.654 & 661.434 & 207.454 & 70.5127 & 51.425 & 29.7862 & 17.6827 & 0.25502 \\
\hline 10.27 & 6.283 & 2.915 & 1.176 & 0.7265 & 0.3261 & 0.2517 & 0.06555 \\
\hline 394.068 & 250.472 & 105.639 & 34.253 & 20.6692 & 11.3038 & 7.9133 & 0.03372 \\
\hline 68.457 & 0.26459 & 14.2465 & 0.04997 & 0.15605 & 0.03153 & 0.02184 & 0.03075 \\
\hline 17.982 & 12.272 & 4.611 & 1.87067 & 1.309 & 0.6871 & 0.3964 & 0.04834 \\
\hline 679.783 & 515.956 & 181.535 & 37.0205 & 112.301 & 13.878 & 11.3755 & 0.14316 \\
\hline 58.849 & 38.825 & 17.018 & 6.11283 & 4.50733 & 0.5752 & 1.1852 & 0.02351 \\
\hline 35.988 & 26.385 & 11.2858 & 3.4995 & 2.73233 & 1.1304 & 0.9735 & 0.03197 \\
\hline 244.872 & 171.921 & 69.1678 & 20.9652 & 36.34 & 5.4406 & 4.3377 & 0.05 \\
\hline 1730.89 & 1089.5 & 428.133 & 67.5983 & 89.7313 & 45.0372 & 30.9235 & 0.08571 \\
\hline 11.809 & 7.674 & 3.51275 & 1.41033 & 0.96033 & 0.4629 & 0.2756 & 0.02698 \\
\hline
\end{tabular}




C2-Phenanthrenes/Anthracenes
C3-Benzothiophenes
C3-Chrysenes/Benzanthracenes
C3-Decalins
C3-Dibenzothiophenes
C3-Fluoranthenes/Pyrenes
C3-Fluorenes
C3-Naphthalenes
C3-Naphthobenzothiophenes
C3-Phenanthrenes/Anthracenes
C4-Benzothiophenes
C4-Chrysenes/Benzanthracenes
C4-Decalins
C4-Dibenzothiophenes
C4-Fluoranthenes/Pyrenes
C4-Naphthalenes
C4-Naphthobenzothiophenes
C4-Phenanthrenes/Anthracenes
Carbazole
Chrysene+Triphenylene
cis-Decalin
Dibenz(a,h)anthracene
Dibenz[a,c]anthracene
Dibenz[a,j]anthracene
Dibenzofuran
Dibenzothiophene
Fluoranthene
Fluorene
Indeno(1,2,3-cd)pyrene
Naphthalene
Perylene
Phenanthrene
Picene
Pyrene
Retene
Total PAH_50

\begin{tabular}{|c|c|c|c|c|c|c|c|}
\hline 24.102 & 473.472 & 197.669 & 68.2523 & 17.0017 & 23.3519 & 14.7427 & 0.05222 \\
\hline 24.624 & 0.12972 & 5.37225 & 0.0245 & 0.813 & 0.01546 & 0.01071 & 0.01508 \\
\hline 6.851 & 6.941 & 2.415 & 2.53383 & 0.923 & 0.4472 & 0.2441 & 0.03711 \\
\hline 345.207 & 183.79 & 78.526 & 17.6042 & 24.601 & 6.8703 & 6.2908 & .14832 \\
\hline 28.357 & 24.611 & 11.7868 & 3.74517 & 0.9155 & 0.2905 & 0.6964 & 0.00697 \\
\hline 36.261 & 24.992 & 11.475 & 3.65967 & 2.66317 & 1.3549 & 0.898 & .01498 \\
\hline 248.628 & 174.881 & 75.139 & 23.7478 & 34.3257 & 2.1562 & 4.5463 & 0.04754 \\
\hline 584.44 & 1048.36 & 1157.87 & 130.863 & 83.1853 & 45.1932 & 29.4568 & 0.04106 \\
\hline 5.119 & 4.064 & 1.635 & 0.64233 & 0.449 & 0.2354 & 0.1334 & 0.03035 \\
\hline 185.964 & 129.392 & 56.5195 & 18.0535 & 4.1095 & 6.8873 & 4.1569 & 0.0839 \\
\hline 12.055 & .23117 & 2.48875 & 0.04366 & 0.68567 & 0.02755 & 0.01908 & 0.02687 \\
\hline 0.793 & 2.374 & 0.7655 & 1.14633 & 0.26767 & 0.1518 & 0.055 & 0.01829 \\
\hline 598.745 & 290.623 & 150.973 & 32.4507 & 35.7607 & 13.6879 & 7.3972 & 0.12371 \\
\hline 12.581 & 5.493 & 4.47275 & 1.78 & 0.45217 & 0.0912 & 0.2625 & 0.01893 \\
\hline 20.41 & 14.793 & 6.81725 & 2.079 & 1.48033 & 0.7076 & 0.5543 & 4971 \\
\hline 135.14 & 100.255 & 38.2493 & 16.3932 & 6.95133 & 3.5803 & 2.3271 & 0.01103 \\
\hline 0.743 & 0.946 & 0.53925 & 0.1445 & 0.1455 & 0665 & 0323 & 1406 \\
\hline 155.846 & 115.606 & 57.0595 & 14.4845 & 3.426 & 6.9094 & 3.5269 & 0.08278 \\
\hline 0.03711 & 0.03729 & 0.02639 & 0.02515 & 0.00656 & 0.01213 & 00368 & 1681 \\
\hline 17.099 & 10.468 & 4.5225 & 54933 & 0.99 & 39 & 2976 & 0.00601 \\
\hline 0.23191 & 0.17055 & 0.03762 & 0.03221 & 0.10059 & .02032 & 01408 & 01982 \\
\hline 0.5 & 0.5 & 0.125 & 0.08333 & 0.08333 & 0.05 & 0.05 & 0.05 \\
\hline 0.475 & 0.311 & 0.13625 & 0.02163 & 0.01813 & 9944 & 154 & 1132 \\
\hline .22141 & 0.07191 & 0.05532 & 0.02887 & 0.02419 & 0.01259 & 0.00532 & 0.01511 \\
\hline 9.273 & 6.089 & 8.11175 & 0.64917 & 0.50217 & .2829 & .219 & .0036 \\
\hline 11.724 & 7.208 & 3.52525 & 1.1475 & 0.7675 & 0.4033 & 0.2198 & 0.00473 \\
\hline 3.575 & 2.104 & 1.36975 & 0.356 & 0.22167 & .1454 & .0643 & 0.00273 \\
\hline 56.417 & 38.302 & 14.5573 & 4.39783 & 2.87817 & 1.6504 & 1.0248 & 0.01417 \\
\hline 0.10564 & 0.05 & 0.02639 & 0.01377 & 0.01154 & 0.00601 & 0.005 & 0.00721 \\
\hline 210.439 & 193.488 & 64.786 & 21.6237 & 15.6955 & 10.0294 & 4.8603 & 0.0427 \\
\hline 4.066 & 2.852 & 1.176 & 0.36867 & 0.2365 & 0.1337 & 0.084 & 0.02862 \\
\hline 114.716 & 73.092 & 29.3078 & 9.58867 & 6.3605 & 3.3359 & 2.3532 & 0.03745 \\
\hline 0.17092 & 0.05548 & 0.09725 & 0.02228 & 0.01867 & 0.00972 & 0.0041 & 0.01166 \\
\hline 3.72 & 2.237 & 1.21325 & 0.37383 & 0.23967 & 0.1309 & 0.0723 & 0.0045 \\
\hline 0.251 & 0.251 & 0.10874 & 0.10364 & 0.08194 & 0.04618 & 0.0251 & 0.06093 \\
\hline 7325.55 & 5029.86 & 2727.55 & 575.775 & 450.783 & 215.095 & 142.981 & 0.02791 \\
\hline
\end{tabular}

Supplemental Table 3. PAH concentrations in 100\% HEWAF, and tested dilutions in Experiment 2 , at beginning of exposure $(\mathrm{t}=0)$ and after 48 hours $(\mathrm{t}=48)$. All units in $\mu \mathrm{g} / \mathrm{L}$.

\begin{tabular}{lrrrrrrrr}
\multicolumn{1}{c}{ chemical_name } & 100x t0 & 100x t48 & $2.7 x$ t0 & $2.7 x$ t48 & $0.9 x$ t0 & $0.9 x$ t48 & $0.3 x$ t0 & $0.3 x$ t48 \\
& & & & & & & & \\
1,2-Dimethylnaphthalene & 70.1740 & 69.2720 & 4.2555 & 1.2860 & 0.6290 & 0.4859 & 0.2141 & 0.1777 \\
1,3+1,6-Dimethylnaphthalene & 600.9890 & 601.7630 & 32.2185 & 10.8214 & 5.4624 & 4.5329 & 1.9777 & 1.5012 \\
1,4,6- and 2,3,6-Trimethylnaphthalene & 246.7780 & 233.8830 & 5.6061 & 4.7961 & 2.0535 & 2.6777 & 0.7749 & 0.6067 \\
1,4-Dimethylnaphthalene & 74.0630 & 105.3890 & 6.8383 & 1.9912 & 0.8085 & 0.7053 & 0.3541 & 0.2814 \\
1,5-Dimethylnaphthalene & 92.5060 & 92.7340 & 6.1127 & 1.7242 & 0.8522 & 0.7430 & 0.2956 & 0.2288 \\
1,6,7 Trimethylnaphthalene & 165.8450 & 168.5220 & 3.7631 & 3.3195 & 1.3613 & 1.6158 & 0.4231 & 0.3378 \\
1,8-Dimethylnaphthalene & 36.2810 & 37.7640 & 4.4057 & 0.6737 & 0.2960 & 0.4182 & 0.1061 & 0.1036 \\
11H-Benzo(a)fluorene & 4.1660 & 4.4660 & 0.1013 & 0.1144 & 0.0463 & 0.0757 & 0.0128 & 0.0129 \\
11H-Benzo(b)fluorene & 14.7510 & 13.5600 & 0.3769 & 0.3421 & 0.1413 & 0.2852 & 0.0442 & 0.0404 \\
1-Methylanthracene & 8.3420 & 7.7830 & 0.2101 & 0.1623 & 0.0741 & 0.1195 & 0.0240 & 0.0197 \\
1-Methyldibenzothiophene & 19.3440 & 19.0830 & 0.5415 & 0.4379 & 0.1801 & 0.2622 & 0.0567 & 0.0476 \\
1-Methylfluorene & 112.0380 & 118.7840 & 4.0281 & 2.5700 & 1.1234 & 1.3831 & 0.3484 & 0.2839 \\
1-Methylnaphthalene & 499.8680 & 506.9740 & 5.9652 & 9.8905 & 4.4446 & 3.0078 & 1.6418 & 1.3235
\end{tabular}




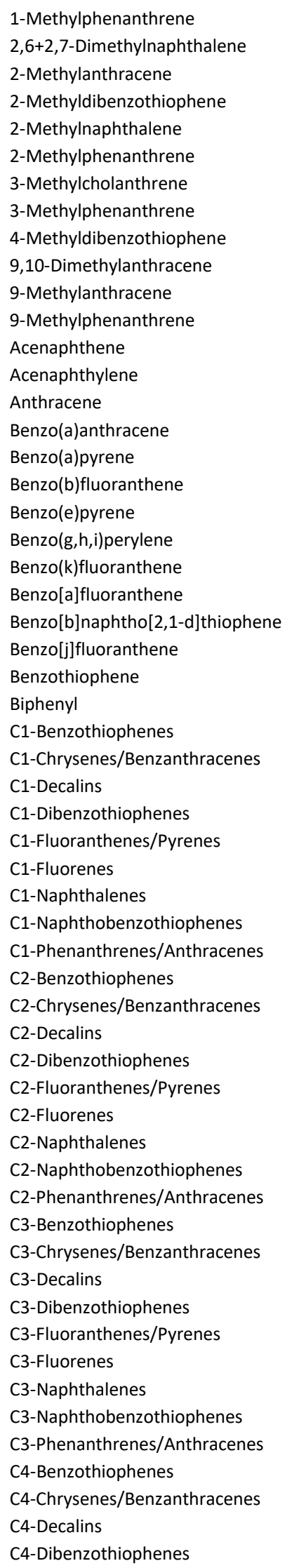

\begin{tabular}{|c|c|c|c|c|c|c|c|}
\hline 97.4050 & 96.1390 & 2.6206 & 2.2000 & 0.9095 & 1.3903 & 0.2860 & 0.2424 \\
\hline 232.0150 & 251.4220 & 12.1705 & 3.9941 & 2.2053 & 1.3028 & 0.7146 & 0.4922 \\
\hline 6.6210 & 7.5480 & 0.1602 & 0.1647 & 0.0689 & 0.1257 & 0.0248 & 0.0237 \\
\hline 12.5620 & 13.2740 & 0.3564 & 0.2822 & 0.1265 & 0.1802 & 0.0364 & 0.0306 \\
\hline 678.0370 & 709.5800 & 6.7594 & 13.1679 & 6.1219 & 4.2009 & 2.2621 & 1.7332 \\
\hline 102.5820 & 100.1550 & 2.8008 & 2.3824 & 0.9758 & 1.5777 & 0.3057 & 0.2566 \\
\hline 0.8430 & 1.0140 & 0.0224 & 0.0270 & 0.0094 & 0.0202 & 0.0030 & 0.0029 \\
\hline 117.0160 & 115.4570 & 3.1270 & 2.6777 & 1.0687 & 1.7079 & 0.3493 & 0.2957 \\
\hline 50.4170 & 49.2500 & 1.3536 & 1.1638 & 0.4668 & 0.7103 & 0.1530 & 0.1294 \\
\hline 0.0305 & 0.0308 & 0.0021 & 0.0011 & 0.0002 & 0.0003 & 0.0003 & 0.0002 \\
\hline 0.0088 & 0.0090 & 0.0006 & 0.0003 & 0.0001 & 0.0001 & 0.0001 & 0.0001 \\
\hline 119.4590 & 117.3300 & 3.2388 & 2.6896 & 1.1587 & 1.7311 & 0.3559 & 0.3016 \\
\hline 0.0471 & 0.0531 & 0.0091 & 0.0018 & 0.0004 & 0.0005 & 0.0004 & 0.0004 \\
\hline 17.8310 & 19.0160 & 0.7981 & 0.3214 & 0.0001 & 0.1981 & 0.0511 & 0.0377 \\
\hline 5.5270 & 5.4810 & 0.1392 & 0.1245 & 0.0547 & 0.0904 & 0.0158 & 0.0133 \\
\hline 3.5840 & 3.6760 & 0.0965 & 0.0936 & 0.0359 & 0.0757 & 0.0108 & 0.0098 \\
\hline 0.5330 & 0.5890 & 0.0135 & 0.0123 & 0.0053 & 0.0107 & 0.0017 & 0.0013 \\
\hline 2.1990 & 2.0080 & 0.0487 & 0.0488 & 0.0211 & 0.0378 & 0.0066 & 0.0065 \\
\hline 3.9340 & 3.8310 & 0.0964 & 0.0986 & 0.0376 & 0.0836 & 0.0117 & 0.0113 \\
\hline 0.6990 & 0.7630 & 0.0164 & 0.0181 & 0.0059 & 0.0142 & 0.0022 & 0.0024 \\
\hline 0.0500 & 0.0500 & 0.0020 & 0.0020 & 0.0005 & 0.0005 & 0.0005 & 0.0005 \\
\hline 0.3500 & 0.3650 & 0.0095 & 0.0087 & 0.0033 & 0.0062 & 0.0011 & 0.0011 \\
\hline 4.7920 & 4.8360 & 0.1260 & 0.1156 & 0.0432 & 0.0940 & 0.0123 & 0.0122 \\
\hline 0.0320 & 0.0320 & 0.0013 & 0.0013 & 0.0003 & 0.0003 & 0.0003 & 0.0003 \\
\hline 0.0595 & 0.0667 & 0.3425 & 0.0023 & 0.0006 & 0.0008 & 0.0005 & 0.0005 \\
\hline 75.5910 & 81.3240 & 2.0001 & 1.4684 & 0.7168 & 0.5352 & 0.2391 & 0.1907 \\
\hline 49.7220 & 48.2530 & 11.6560 & 0.6273 & 0.3366 & 0.3873 & 0.1271 & 0.0689 \\
\hline 24.6040 & 23.2340 & 0.6672 & 0.6235 & 0.2383 & 0.4765 & 0.0686 & 0.0642 \\
\hline 885.2940 & 799.8320 & 6.6218 & 8.8735 & 5.3600 & 2.8373 & 2.0577 & 1.2206 \\
\hline 101.0220 & 98.6400 & 2.7788 & 2.3334 & 0.9387 & 1.3878 & 0.2996 & 0.2573 \\
\hline 20.0180 & 18.4470 & 0.4873 & 0.5260 & 0.1903 & 0.3790 & 0.0564 & 0.0498 \\
\hline 291.8070 & 314.7220 & 10.8213 & 6.8323 & 2.8435 & 4.1244 & 0.9495 & 0.7890 \\
\hline 1220.3350 & 1232.8740 & 11.6456 & 24.5752 & 11.3189 & 8.0529 & 4.0294 & 3.1474 \\
\hline 15.0650 & 15.8720 & 0.4405 & 0.3950 & 0.1528 & 0.3247 & 0.0415 & 0.0390 \\
\hline 470.8320 & 450.5030 & 12.6806 & 10.7438 & 4.3674 & 6.7115 & 1.3789 & 1.1750 \\
\hline 59.5080 & 35.4390 & 0.9667 & 1.4617 & 0.3929 & 0.7752 & 0.2334 & 0.1156 \\
\hline 23.8340 & 20.5250 & 0.6355 & 0.6512 & 0.1943 & 0.4215 & 0.0656 & 0.0635 \\
\hline 840.2490 & 718.8850 & 19.1676 & 9.2329 & 5.7362 & 3.3795 & 1.9366 & 1.1537 \\
\hline 119.1990 & 118.2040 & 3.4999 & 2.8169 & 1.2082 & 2.0015 & 0.3437 & 0.3112 \\
\hline 86.8550 & 79.8200 & 1.9596 & 1.9514 & 0.8689 & 1.6572 & 0.2520 & 0.2112 \\
\hline 213.0040 & 223.2910 & 8.3444 & 5.0070 & 2.1174 & 3.7030 & 0.6548 & 0.5710 \\
\hline 1771.4480 & 1782.5400 & 98.1035 & 32.1208 & 16.1610 & 13.8418 & 5.7502 & 4.3488 \\
\hline 17.0690 & 16.7060 & 0.5275 & 0.4542 & 0.1615 & 0.3600 & 0.0464 & 0.0429 \\
\hline 933.7340 & 911.0260 & 25.7468 & 21.4372 & 8.9655 & 16.0181 & 2.6545 & 2.3946 \\
\hline 10.1250 & 8.6740 & 10.2089 & 0.1538 & 0.0639 & 0.2240 & 0.0250 & 0.0267 \\
\hline 14.9190 & 12.0270 & 0.4413 & 0.4109 & 0.1137 & 0.2127 & 0.0417 & 0.0410 \\
\hline 322.7050 & 278.5680 & 26.4831 & 3.7410 & 2.1884 & 2.0608 & 0.6821 & 0.4362 \\
\hline 77.3680 & 77.7340 & 2.3669 & 1.8119 & 0.7415 & 1.3554 & 0.2161 & 0.1933 \\
\hline 86.0830 & 80.2160 & 2.0578 & 1.9926 & 0.8483 & 1.5575 & 0.2312 & 0.2140 \\
\hline 272.4970 & 293.5640 & 11.4180 & 6.7693 & 2.8694 & 5.2114 & 0.8013 & 0.7162 \\
\hline 1289.5650 & 1260.3380 & 35.4571 & 23.9075 & 11.0505 & 14.5411 & 4.7359 & 3.6666 \\
\hline 7.3360 & 6.9000 & 0.2564 & 0.1926 & 0.0635 & 0.1366 & 0.0181 & 0.0182 \\
\hline 269.9950 & 244.0080 & 7.0475 & 5.9267 & 2.5078 & 4.3507 & 0.7427 & 0.6631 \\
\hline 13.1540 & 14.3720 & 0.9675 & 0.2379 & 0.1008 & 0.2347 & 0.0327 & 0.0246 \\
\hline 5.2240 & 5.5790 & 0.1607 & 0.1556 & 0.0394 & 0.0755 & 0.0132 & 0.0193 \\
\hline 376.1180 & 345.7150 & 103.2344 & 5.7496 & 3.2116 & 2.8019 & 1.0458 & 0.6632 \\
\hline 32.8860 & 38.6410 & 1.1247 & 0.8941 & 0.4018 & 0.6403 & 0.1027 & 0.0995 \\
\hline
\end{tabular}




C4-Fluoranthenes/Pyrenes
C4-Naphthalenes
C4-Naphthobenzothiophenes
C4-Phenanthrenes/Anthracenes
Carbazole
Chrysene+Triphenylene
cis-Decalin
Dibenz(a,h)anthracene
Dibenzofuran
Dibenzothiophene
Fluoranthene
Fluorene
Indeno(1,2,3-cd)pyrene
Naphthalene
Perylene
Phenanthrene
Pyrene
Retene
Total PAH_50

$\begin{array}{rrrrrrrr}47.4500 & 47.9610 & 1.1193 & 1.2299 & 0.5058 & 0.9123 & 0.1282 & 0.1178 \\ 160.0960 & 162.6730 & 5.1734 & 4.0156 & 1.4164 & 2.6411 & 0.5261 & 0.3756 \\ 3.5570 & 2.9210 & 0.1185 & 0.0792 & 0.0261 & 0.0503 & 0.0081 & 0.0093 \\ 242.7460 & 173.3800 & 4.9715 & 5.0254 & 2.1779 & 3.8735 & 0.5955 & 0.5033 \\ 0.0100 & 0.0100 & 0.0005 & 0.0004 & 0.0001 & 0.0001 & 0.0001 & 0.0001 \\ 22.0250 & 22.0690 & 0.5609 & 0.5404 & 0.2097 & 0.4288 & 0.0645 & 0.0590 \\ 0.1738 & 0.1951 & 1.0010 & 0.0068 & 0.0016 & 0.0022 & 0.0015 & 0.0014 \\ 0.0500 & 0.0500 & 0.0020 & 0.0020 & 0.0005 & 0.0005 & 0.0005 & 0.0005 \\ 10.2490 & 10.3160 & 0.1848 & 0.2244 & 0.0913 & 0.0760 & 0.0370 & 0.0291 \\ 20.8200 & 20.5110 & 0.5117 & 0.4588 & 0.2016 & 0.2083 & 0.0658 & 0.0542 \\ 4.3050 & 4.1360 & 0.1797 & 0.1095 & 0.0421 & 0.0798 & 0.0136 & 0.0122 \\ 60.4840 & 56.8220 & 1.5207 & 1.2368 & 0.5397 & 0.4805 & 0.1878 & 0.1526 \\ 0.0500 & 0.0500 & 0.0020 & 0.0020 & 0.0005 & 0.0005 & 0.0005 & 0.0005 \\ 422.8900 & 440.0770 & 5.0519 & 8.7646 & 3.7109 & 2.6882 & 1.3626 & 1.0925 \\ 0.1460 & 0.2120 & 0.0020 & 0.0044 & 0.0014 & 0.0023 & 0.0006 & 0.0006 \\ 129.6710 & 124.9130 & 3.2668 & 2.7960 & 1.1434 & 1.2940 & 0.4021 & 0.3266 \\ 5.4050 & 5.2520 & 0.1286 & 0.1263 & 0.0532 & 0.0909 & 0.0170 & 0.0151 \\ 0.0504 & 0.0510 & 0.0033 & 0.0020 & 0.0004 & 0.0005 & 0.0005 & 0.0004 \\ 8609.4370 & 8518.3310 & 264.8012 & 179.4458 & 79.4047 & 101.5104 & 27.2542 & 22.1295\end{array}$

